\title{
Study of heat exchange processes in a screw ash cooler installation
}

\author{
Barbara Janowska ${ }^{1, *}$, Pawet Regucki ${ }^{1}$, Artur Andruszkiewicz ${ }^{1}$, and Wiesław \\ Wędrychowicz ${ }^{1}$ \\ ${ }^{1}$ Wrocław University of Science and Technology, Faculty of Mechanical and Power Engineering, \\ Wybrzeże Wyspiańskiego 27, 50-370 Wrocław, Poland
}

\begin{abstract}
The paper presents an example of the thermal-flow analysis of a bottom ash cooler cooperating with a circulating fluidized bed (CFB) boiler. The authors present the methodology of the conducted studies and examples of thermal balance calculations basing on measurement results. The comparison of two different ash coolers indicates a significant relationship between the outlet temperatures of the ash and cooling water depending on the construction and arrangement of the analysed ash coolers. The analysis presented in this paper enables determining the optimal rotation speed of the screw in order to achieve the required temperature of the slag depending on the actual working parameters of the CFB boiler. It provides an opportunity to optimize the heat exchange conditions in order to obtain the highest acceptable water temperature at the outlet of the ash cooler while adhering to safety regulations. The hot water could further be used for internal sanitary purposes or to support heating systems operating in the power plant.
\end{abstract}

\section{Introduction}

Conventional and thermal power plants are the major producers of electricity and heat in the world power engineering sector. Their period of operation, which is often calculated at $30-40+$ years, has a significant impact on the natural environment, as well as on the health and functioning of local communities [1]. The long utilisation period under varying heat-flow conditions signifies that power units require continuous maintenance and improvement of exhaust gas purification technologies [2].

Campbell et al. in [3] have stated that the efficiency of coal-fired power plants decreases with age. Although the continuity of maintenance practices can keep a power plant's efficiency high in the early years of operation, the long-term utilization of the boilers and their auxiliary systems leads to the gradual degradation of their performance as a result of e.g. corrosion or deposition of heat exchange surfaces, leakages in water-steam systems or the deterioration of pump characteristics.

\footnotetext{
${ }^{*}$ Corresponding author: barbara.janowska@pwr.edu.pl
} 
On the other hand, the deterioration of the overall efficiency of power units manifests in the increased consumption of fossils, which has a direct influence on the increase of the production of wastewater, waste heat, as well as greenhouse gases and other pollutants.

Henderson in [4] has stated that the improvement of the efficiency of a large number of older coal- and oil-fired power plants operating around the world would provide major savings in $\mathrm{CO}_{2}$ emission. In order to improve the overall efficiency of old power units, Ryabchikov et al. in [5] have suggested a number of specific actions connected with e.g. the raising of heat exchanger efficiency, the retrofit of hydraulic systems and the improvement or sustenance of their reparability and maintainability. Błaszczyk et al. in [6] have found that the overall efficiency of a power plant encompasses the efficiencies of the various power unit components. Among others, they have pointed out that heat loss minimization is the most important factor affecting the loss of power plant efficiency, and there are many areas of potential heat loss in a power plant.

These observations and comments have led to the Authors focusing their attention on an analysis of the thermal-flow processes taking place in ash coolers. Ash coolers are used for the preliminary cooling down of the slag produced in CFB boilers. As a result of combustion processes, hot slag is produced and then must be removed from the combustion chamber and pre-cooled before final storage. Moreover, the mass flow rate of extracting slag is used to control the pressure in the dense fluidized layer above the primary air nozzle grid in the furnace of the CFB boiler. The mass flow rate of the discharged slag can vary from a few to several $\mathrm{kg} / \mathrm{s}$, depending on the types of boilers and their nominal power, as well as on the mass flow rate and technical analysis of the fuel. For technical reasons, the slag transported from the boiler must be cooled down to a temperature of about $100-150^{\circ} \mathrm{C}$. The construction, number and location of the ash coolers are closely related to the combustion chamber type and are important elements of any power boiler [7]. Studies and measurements indicate that the ash coolers are a significant source of waste heat [8]. Nichols et al. in [9] have estimated that the potential efficiency improvement for power plants in the USA resulting from the revitalization of the ash removal system would be at a level of $0.1 \%$.

In the relevant literature, different types of fluidized bed ash coolers $[10,11]$ have been analysed, together with an estimation of their influence on the thermal economy of the power unit [12]. In the presented paper, two different types of ash coolers cooperating with a CFB boiler are considered. Following a discussion of the study's methodology, examples of thermal balance calculations basing on the measurement results are analysed. This enables determining the optimal heat exchange conditions required to achieve the necessary temperature of the ash depending on the actual working parameters of the boiler.

\section{Construction of bottom ash coolers}

\subsection{Two screw bottom ash cooler}

Among the many types of bottom ash coolers utilized in power plants operating with a CFB boiler, the solution based on two screws is very popular. In the considered case, due to security reasons, the circulating fluidized bed boiler is equipped with two independent bottom ash coolers (called SAC-L and SAC-R, respectively, for the left and right bottom ash cooler). Figure 1 provides a schematic image of the most important elements of a SAC-R ash cooler - two screws designated by the acronyms SC-L and SC-R on the left scheme. The right part of Figure 1 presents a side view of the bottom ash cooler with an indication of the hot slag inlet (1), the outlet of the cooled slag (6), the inlet and the outlet of the cooling water flowing through the shaft and blades of the SC-L screw (respectively (2) and (3)), the inlet and the 
outlet of the cooling water which flows between the walls (casing) of the ash cooler (respectively (4) and (5)).

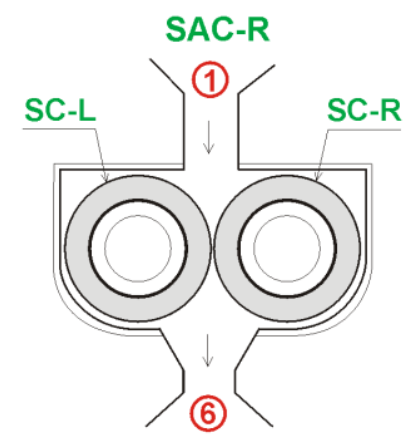

\section{SAC-R}

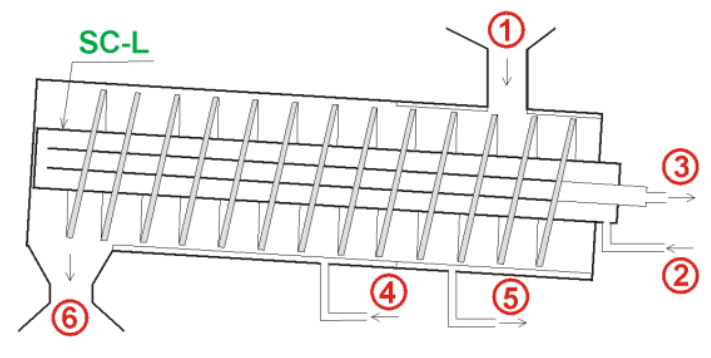

Fig. 1. Scheme of the bottom ash cooler (SAC-R) with internal cooling water distribution: two screws (SC-L and SC-R), the inlet and the outlet of the slag (1 and 6 respectively), the inlet and the outlet of the cooling water (2, 4 and 3,5 respectively).

The hot slag is delivered directly from the combustion chamber (1), after which it is split between two screw coolers (SC-L and SC-R), and then transported to point (6). The mass flow rate of the removed slag is controlled by the rotation speed of the screws. During its movement along the screw, the slag is gradually cooled by the cooling water circulating in the blades, the shaft and between the walls (the casing). The mass flow rates of the cooling water are constant and independent of the rotation speed of the screws.

\subsection{Bottom ash cooler with a single screw}

The other construction of the bottom ash cooler is based on a single screw solution. The geometrical parameters of this type of ash cooler are smaller than in the above-presented case of the two screw ash cooler. Thus, single screw ash (SSA) coolers are usually arranged in a set of a few units in order to satisfy the thermal requirements of the CFB boiler. Such a solution provides the additional possibility of removing the hot ash from selected locations in the combustion chamber's bottom. The scheme of a bottom ash cooler with a single screw is presented in Figure 2.

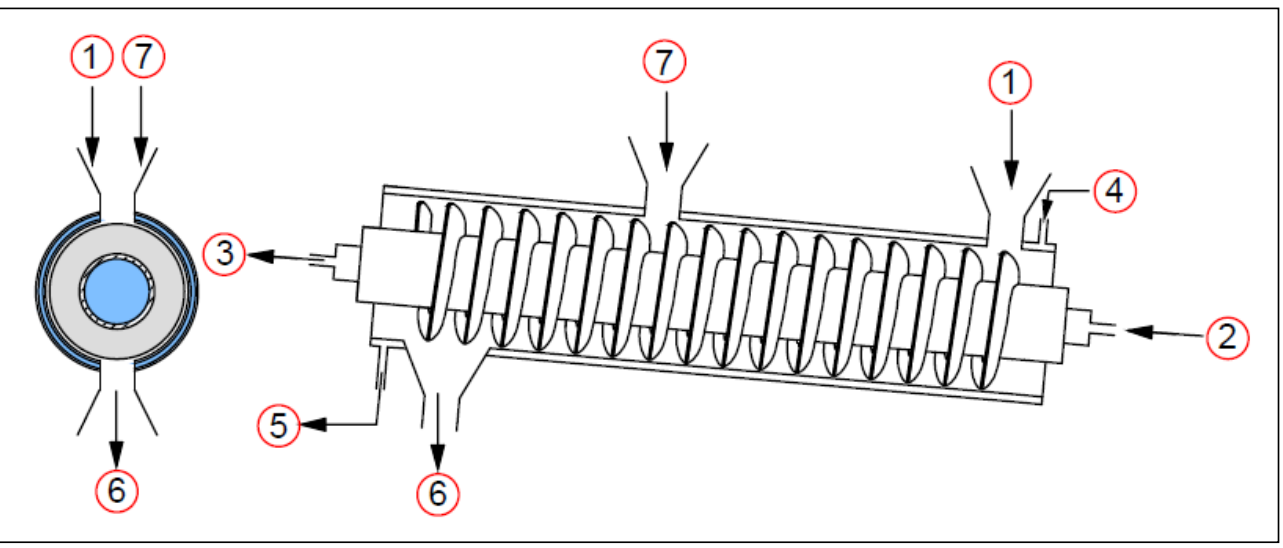

Fig. 2. Scheme of a bottom ash cooler with a single screw: the inlets and the outlet of the slag (respectively 1, 7 and 6), the inlets and the outlets of the cooling water (respectively 2, 4 and 3,5 ). 
This type of bottom ash cooler has two hot slag inlets: at the beginning and in the middle of the screw. Under normal operational conditions, only the inlet at the beginning of the screw is used, but sometimes the hot ash is delivered also through the middle inlet, connected with Intrex-type superheaters by ash removal channels. The volumetric flow rates of the cooling water circulated in screw ash coolers are constant over time. An example of the arrangement of eight SSA coolers is shown in Figure 3.

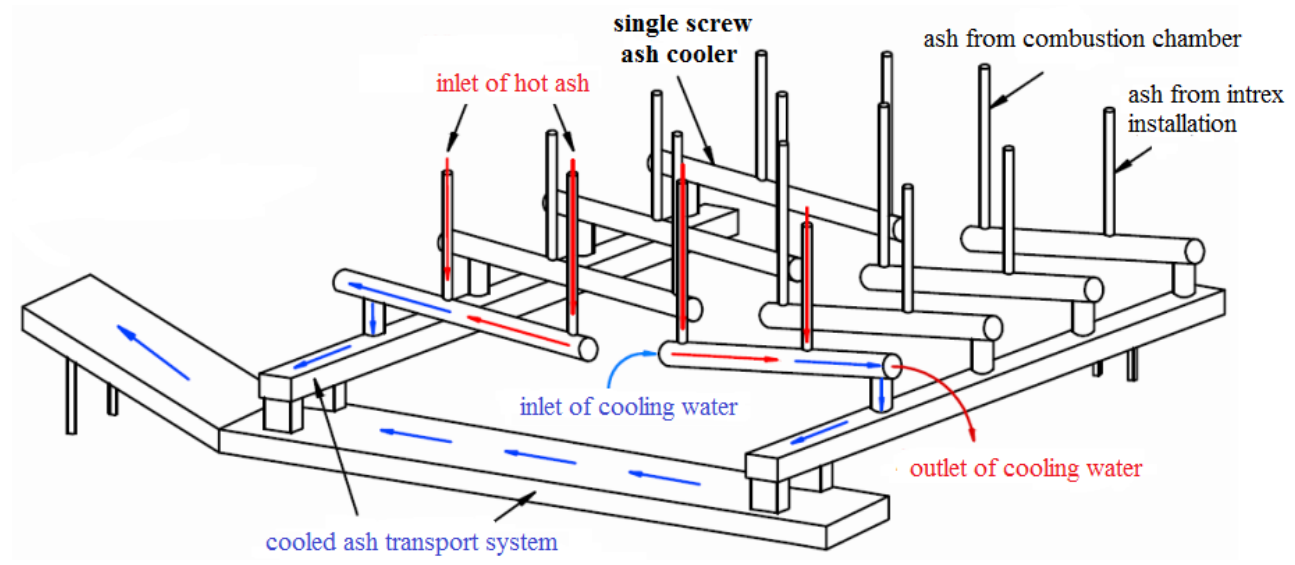

Fig. 3. Scheme of eight single ash coolers linked with a CFB boiler.

\section{Measurements and comments}

The analysis of the thermal flow processes occurring in the bottom ash coolers presented in this paper is based on measurement data collected on real objects. The volumetric flow rates were measured by an ultrasonic flowmeter (Microsonic Portaflow330), while the thickness of the pipe walls using a thickness gauge (Metrisonic SONO M610). Three different methods were applied to conduct the temperature measurements:

- the PT100 contact thermometer,

- the LaserLiner ThermoSpot-Vision optical pyrometer,

- the TESTO 875-2 infrared camera.

The total heat flux transferred from the hot ash to the cooling water was calculated using the following formula (in $\mathrm{kW}$ ):

$$
\mathrm{Q}=c_{w} \sum_{\mathrm{k}} \Delta \mathrm{t}_{\mathrm{w}, \mathrm{k}} \cdot \mathrm{q}_{\mathrm{v}, \mathrm{k}} \cdot \rho_{\mathrm{w}}=c_{a} \cdot \Delta \mathrm{t}_{a} \cdot \mathrm{q}_{\mathrm{m}, a}
$$

where: $c_{w}$ and $c_{a}$ is the specific heat of the water and the ash, respectively (in $\mathrm{kJ} / \mathrm{kg} \cdot \mathrm{K}$ ); $\Delta t_{w}$ and $\Delta t_{a}$ - the temperature difference of the cooling water and the ash, respectively, calculated at the inlets and outlets of the ash cooler; $q_{v, k}$ - the volumetric flow rates of the cooling water flowing through the screws and outer walls, respectively (in $\mathrm{m}^{3} / \mathrm{s}$ ); $q_{m, a}$ - the mass flow rate of the ash (in $\mathrm{kg} / \mathrm{s}$ ); $\rho_{w}$ - the density of the water calculated for individual temperatures of the cooling water.

In all the calculations, the values of specific heats were used, equal to $c_{a}=0.958 \mathrm{~kJ} / \mathrm{kg} \cdot \mathrm{K}$ and $c_{w}=4.190 \mathrm{~kJ} / \mathrm{kg} \cdot \mathrm{K}$. The value of the water density was calculated for the particular temperature of the cooling water and oscillated between 998.2 and $971.8 \mathrm{~kg} / \mathrm{m}^{3}$ (for $t_{w}$ equals 20 and $80^{\circ} \mathrm{C}$, respectively). 


\subsection{Two screw bottom ash cooler}

Table 1 presents the mean temperatures of the cooling water and ash measured at the outlets of the SAC-R ash cooler versus the ash load of the cooler $\mathrm{L}_{\text {ash. }}$. The symbols $\mathrm{t}_{\text {out,SC-L }}$ and $t_{\text {out,SC-R }}$ denote the outlet temperatures of the water from the left and right screw coolers, respectively (see Fig. 1), and $t_{\text {out,wall }}$ - the outlet temperature of the water flowing between the outer walls (casing). The symbols $t_{\text {in,ash }}$ and $t_{\text {out,ash }}$ denote the inlet and the outlet temperatures of the ash, respectively. The ash load $\mathrm{L}_{\text {ash }}$ is expressed in the percentage of the nominal (design) load of ash cooler.

Table 1. Mean temperatures of the cooling water and ash measured at the outlets of the SAC-R ash cooler versus the ash load of the cooler $\mathrm{L}_{\text {ash. }}$.

\begin{tabular}{|c|c|c|c|c|c|c|}
\hline \multirow{2}{*}{$\begin{array}{c}\text { ash load } \\
\mathrm{L}_{\text {ash, }}\end{array}$} & \multirow{2}{*}{$\begin{array}{c}\text { rotation } \\
\text { speed of } \\
\text { screw } \omega, \mathrm{rpm}\end{array}$} & \multicolumn{3}{|c|}{$\begin{array}{c}\text { outlet temperature } \\
\text { of cooling water, }\end{array}$} & \multicolumn{2}{|c|}{ temperature of ash, ${ }^{\circ} \mathrm{C}$} \\
\cline { 3 - 7 } & 2.04 & $\mathrm{t}_{\text {out,SC-L }}$ & $\mathrm{t}_{\text {out,SC-R }}$ & $\mathrm{t}_{\text {out,wall }}$ & $\mathrm{t}_{\text {in,ash }}$ & $\mathrm{t}_{\text {out,ash }}$ \\
\hline 20 & 35.2 & 35.5 & 40.6 & 391.9 & 69.7 \\
\hline 40 & 4.08 & 42.5 & 41.6 & 47.3 & 515.3 & 82.3 \\
\hline 60 & 6.12 & 47.0 & 46.0 & 53.9 & 581.3 & 130.7 \\
\hline 90 & 9.18 & 51.7 & 52.4 & 70.8 & 592.8 & 209.8 \\
\hline
\end{tabular}

The volumetric flow rates $q_{v, S C-L}, q_{v, S C-R}$ and $q_{v \text {,wall }}$ were constant over time and equaled $19.56,18.91$ and $13.25 \mathrm{~m}^{3} / \mathrm{h}$, respectively. The inlet temperature of the cooling water fluctuates in a range of between 31.8 and $33.0^{\circ} \mathrm{C}$. Comparing the outlet temperatures of the cooling water, one can note that the highest are obtained in the flow between the outer walls of the cooler. Despite this, the mean temperature of the water leaving the ash cooler, calculated over the volumetric flow rates, oscillates at between 38.7 and $51.1^{\circ} \mathrm{C}$ (for 20 and $90 \%$ of the ash load, respectively). Such a range of temperatures is useless for direct utilisation in sanitary or auxiliary installations. This means that either the heat taken by the cooling water in the ash cooler is released in the cooling towers or the warm water is directed to an additional heating system where its temperature will raise up to $\sim 90^{\circ} \mathrm{C}$. It is worth noting that for $90 \%$ of the ash load the outlet temperature of the ash exceeds the technological limit of $150^{\circ} \mathrm{C}$, which can be dangerous for the ash transport installation.

Table 2 presents the mean values of the heat flux transferred from the hot ash to the cooling water flowing through the left and right screw coolers and outer walls.

Table 2. Mean values of the heat flux transferred from the hot ash to the cooling water flowing through the left and right screws of the SAC-R cooler and outer walls.

\begin{tabular}{|c|c|c|c|c|c|c|}
\hline \multirow{2}{*}{$\begin{array}{c}\text { ash load } \\
\mathrm{L}_{\text {ash, }} \%\end{array}$} & \multirow{2}{*}{$\begin{array}{c}\text { rotation } \\
\text { speed of } \\
\text { screw } \omega, \mathrm{rpm}\end{array}$} & \multicolumn{4}{|c|}{ heat flux to cooling water, $\mathrm{kW}$} & \multirow{2}{*}{$\begin{array}{c}\text { heat flux } \\
\text { from hot } \\
\text { ash, } \mathrm{kW}\end{array}$} \\
\cline { 3 - 7 } & & $\begin{array}{c}\text { through } \\
\text { SC-L }\end{array}$ & $\begin{array}{c}\text { through } \\
\text { SC-R, }\end{array}$ & $\begin{array}{c}\text { through } \\
\text { outer walls }\end{array}$ & total & \\
\hline 20 & 2.04 & 65.5 & 61.7 & 123.8 & 251.0 & 198.2 \\
\hline 40 & 4.08 & 215.3 & 243.1 & 238.5 & 697.0 & 569.0 \\
\hline 60 & 6.12 & 308.8 & 340.9 & 336.0 & 985.8 & 903.0 \\
\hline 90 & 9.18 & 426.1 & 423.5 & 580.0 & 1429.7 & 1219.9 \\
\hline
\end{tabular}

Comparing the data from Table 2, one can find that the relative error between the heat fluxes calculated from formula (1) for the cooling water and the ash ranges from between 8 and $21 \%$. This discrepancy may be due to the fact that a constant value of the specific heat $c_{a}$ was applied to the calculations. It seems that in this case the value typically quoted in the 
relevant literature should be $10 \%$ higher. It is worth noting that $c_{a}$ is strongly dependent on the mineral composition of the burned fuel.

\subsection{Single screw ash cooler}

The thermal-flow measurements presented in this subsection were made on a single screw ash (SSAC) cooler (the left one marked in red and blue in Figure 3). In this construction of the ash cooler, the cooling water flows inside the screw and the outer cover of the ash cooler according to the slag transport direction. Figure 4 shows the relationship between the outlet temperatures of the cooling water from screw $t_{w, s}$ and outer cover $t_{w, c}$ for the SSAC cooler and the $\mathrm{L}_{\text {ash }}$ ash load. The left diagram refers to a situation in which the additional inlet of hot ash in the middle of the screw is closed (closed Intrex installation), while the right one refers to a case involving an open Intrex installation. The volumetric flow rates of water through the screw and outer cover amounted to 3.90 and $6.87 \mathrm{~m}^{3} / \mathrm{h}$, respectively. The inlet temperature of the cooling water for the left and right diagrams was constant, equaling 29.6 and $28.7^{\circ} \mathrm{C}$, respectively.
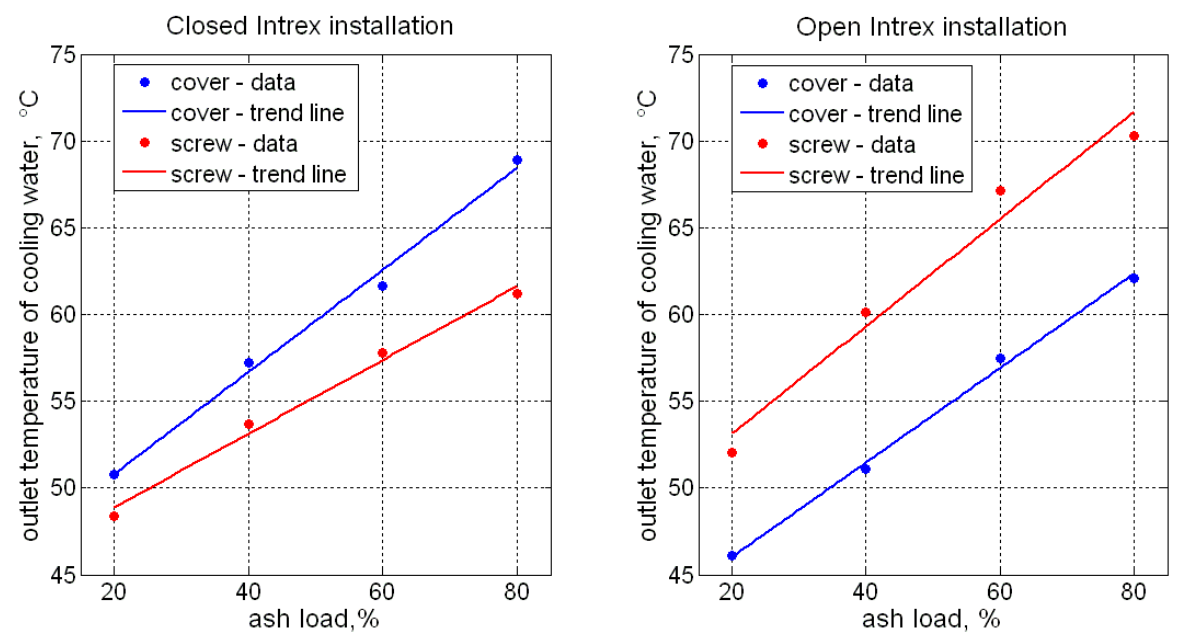

Fig. 4. Outlet temperatures of the cooling water from screw $t_{w, s}$ and outer cover $t_{w, c}$ for the SSAC cooler versus ash load $\mathrm{L}_{\text {ash. }}$. The left diagram refers to a closed Intrex installation, while the right one refers to an open Intrex installation.

The presented results indicate that higher outlet temperatures of the cooling water are obtained in an open Intrex installation (the right diagram). This is due to the additional portion of hot ash added in the middle of the screw. Despite this, the difference between the mean outlet temperatures in both cases is rather small, amounting to $\sim 2{ }^{\circ} \mathrm{C}$. An interesting observation involves the fact that for the open Intrex installation higher temperature values are obtained for cooling water flowing inside the screw, in opposition to the case in which the Intrex installation is closed. This effect could be linked to the fact that in a closed Intrex installation the ash is more efficiently cooled down by the water flowing in the cover (due to the larger surface of heat exchange and volumetric flow rate of the cooling water, as well as the lower ambient temperature), which is confirmed by the data presented in Tables 3 and 4 .

It is worth noting that the highest mean outlet temperature of water obtained for $\mathrm{L}_{\mathrm{ash}}=80 \%$ is approximately $67^{\circ} \mathrm{C}$ (for $\mathrm{L}_{\mathrm{ash}}=60 \%$, it is $60^{\circ} \mathrm{C}$ ). This is a relatively high temperature value, signifying that the hot water can be further used in sanitary installations or in low-temperature heat exchanges. 
Tables 3 and 4 present the mean values of the heat flux transferred from the hot ash to the cooling water flowing through the screw and cover of the SSAC cooler in closed and open Intrex installations, respectively.

Table 3. Mean values of the heat flux transferred from the hot ash to the cooling water flowing through the screw and cover of the SSAC cooler in a closed Intrex installation.

\begin{tabular}{|c|c|c|c|c|c|}
\hline \multirow{2}{*}{$\begin{array}{c}\text { ash load } \\
\mathrm{L}_{\mathrm{ash}}, \%\end{array}$} & \multirow{2}{*}{$\begin{array}{c}\text { rotation } \\
\text { speed of } \\
\text { screw } \omega, \text { rpm }\end{array}$} & \multicolumn{3}{|c|}{ heat flux to cooling water, $\mathrm{kW}$} & \multirow{2}{*}{$\begin{array}{c}\text { heat flux } \\
\text { from hot } \\
\text { ash, kW }\end{array}$} \\
\hline & & $\begin{array}{c}\text { through } \\
\text { screw }\end{array}$ & $\begin{array}{l}\text { through } \\
\text { cover }\end{array}$ & total & \\
\hline 20 & 2 & 144.7 & 109.0 & 253.6 & 244.2 \\
\hline 40 & 4 & 179.4 & 142.3 & 321.7 & 309.8 \\
\hline 60 & 6 & 224.2 & 170.3 & 394.6 & 391.2 \\
\hline 80 & 8 & 258.4 & 183.3 & 441.7 & 423.2 \\
\hline
\end{tabular}

Table 4. Mean values of the heat flux transferred from the hot ash to the cooling water flowing through the screw and cover of the SSAC cooler in an open Intrex installation.

\begin{tabular}{|c|c|c|c|c|c|}
\hline \multirow{2}{*}{$\begin{array}{c}\text { ash load } \\
\mathrm{L}_{\text {ash }}, \%\end{array}$} & \multirow{2}{*}{$\begin{array}{c}\text { rotation } \\
\text { speed of } \\
\text { screw } \omega, \text { rpm }\end{array}$} & \multicolumn{3}{|c|}{ heat flux to cooling water, $\mathrm{kW}$} & \multirow{2}{*}{$\begin{array}{c}\text { heat flux } \\
\text { from ho } \\
\text { ash, kW }\end{array}$} \\
\hline & & $\begin{array}{c}\text { through } \\
\text { screw }\end{array}$ & $\begin{array}{c}\text { through } \\
\text { cover }\end{array}$ & total & \\
\hline 20 & 2 & 166.0 & 83.5 & 249.5 & 262.5 \\
\hline 40 & 4 & 219.7 & 108.8 & 328.5 & 327.9 \\
\hline 60 & 6 & 255.9 & 127.8 & 383.8 & 392.4 \\
\hline 80 & 8 & 293.6 & 167.9 & 461.5 & 462.5 \\
\hline
\end{tabular}

In the case of a closed Intrex installation, the overall heat fluxes are always lower than for an open Intrex installation. This is because extra hot ash is added in the middle of the ash cooler. The relative error between the heat fluxes calculated for the cooling water and the hot ash in both tables varies by less than $5 \%$. Figure 5 presents the outlet temperatures of the ash in closed and open Intrex installations.
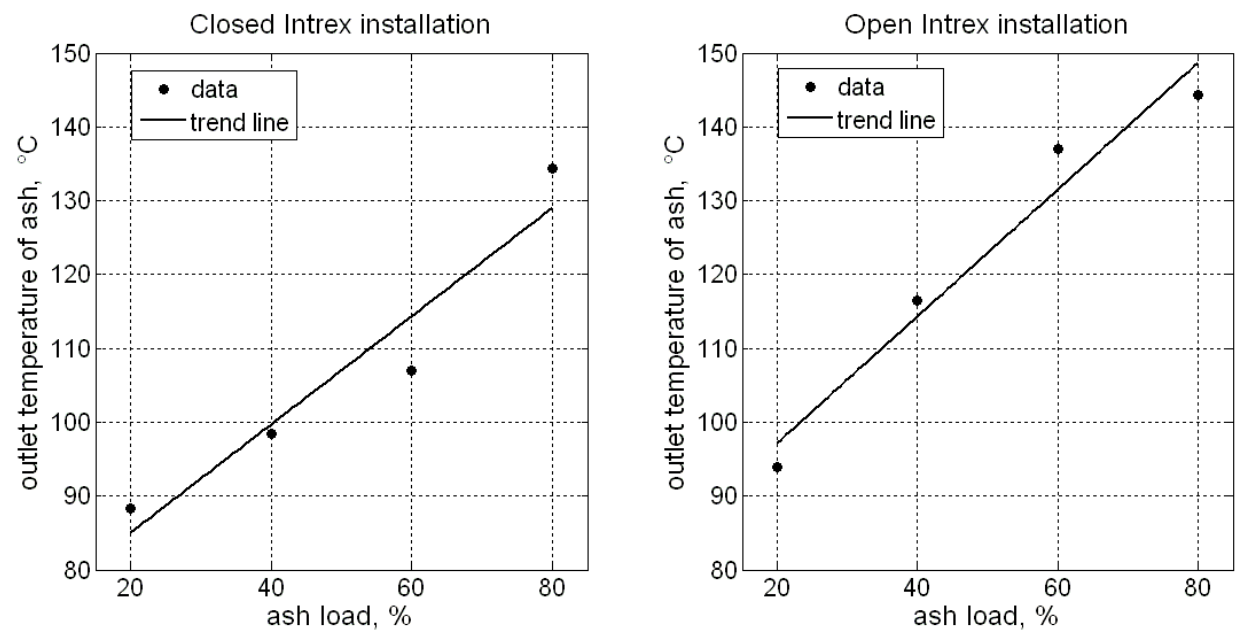

Fig. 5. The outlet temperatures of the ash from the SSAC cooler versus the ash load Lash. The left diagram refers to a closed Intrex installation, the right one - to an open Intrex installation. 


\section{Closing remarks}

The presented analysis of two examples of ash coolers indicates that the amount of heat transferred from the hot slag to the cooling water is relatively high. In the case of the two screw bottom ash cooler, the heat flux varies from 0.25 up to $1.43 \mathrm{MW}$, which is a significant value in the thermal balance of a boiler. Unfortunately, the outlet temperatures of the cooling water are below $52^{\circ} \mathrm{C}$; thus, it is impossible to directly utilize this source of waste heat efficiently in the sanitary or auxiliary installations of a power unit. This means that either the heat taken by the cooling water in the ash cooler is released into the atmosphere in the cooling towers or the warm water is directed to an additional heating system (e.g. in secondary heat exchanger) where its temperature will increase up to useful range $\left(\sim 70-90^{\circ} \mathrm{C}\right)$.

In the case of the single screw ash cooler, higher values of the outlet temperatures of the cooling water could be achieved. This type of ash cooler can deliver water with an outlet temperature at a level of $60-67^{\circ} \mathrm{C}$ and, at the same time, preserve the restriction imposed on the outlet temperature of the slag at the required level (below $150^{\circ} \mathrm{C}$ ). The warm water from this heat exchanger could be utilized in the sanitary or auxiliary installations of a power unit. The only disadvantage lies in the insufficient value of the water's volumetric flow rate. In the first case, the volumetric flow rate of the cooling water through the ash cooler amounts to approx. $52 \mathrm{~m}^{3} / \mathrm{h}$, while in the other case - only $11 \mathrm{~m}^{3} / \mathrm{h}$.

\section{References}

1. S. Fleischli, https://www.nrdc.org/experts/steve-fleischli/message-epa-time-modernizeamericas-power-plants-cooling-systems-included (Last cited 4 January 2016)

2. R.J. Campbell, P. Folger, Ph. Brown, Cong. Res. Serv. Report, R42950 (2013)

3. R.J. Campbell, Cong. Res. Serv. 7-5700 (2013)

4. C. Henderson, http://www.iea-coal.org.uk/documents/83185/8784/Upgrading-andefficiency-improvement-in-coal-fired-power-plants,-CCC/221 (2012)

5. A. Yu. Ryabchikov, K.É. Aronson, Yu.M. Brodov, S.I. Khaet, S.N. Blinkov, N.V. Zhelonkin, Power Technol. Eng. 44, 3 (2010)

6. A. Błaszczyk, J. Głuch, A. Gardzilewicz, Polish Maritime Res. 18, 3 48-54 (2011)

7. M.A. Malek, Heating boiler operator's manual: maintenance, operation and repair (McGraw-Hill, New York, 2007)

8. P. Regucki, A. Andruszkiewicz, W. Wędrychowicz, B. Engler, J. Perspectives in Science 7, 353-356 (2016)

9. C. Nichols, G. Vaux, C. Zaremsky, J. Murphy, M. Ramezan, DOE/NETL-2008/1329 (2008)

10. Z. Man, B. Rushan, X. Qinggui, Powder Technol. 201, 114-122 (2010) DOI: 10.1016/j.powtec.2010.03.004

11. B. Zeng, X. Lu, L. Gan, M. Shu, Powder Technol. 212, 151-160 (2011) DOI: 10.1016/j.powtec.2011.05.005

12. B. Zeng, X. Lu, H. Liu, Energy 35, 3863-3869 (2010) DOI: 10.1016/j.energy.2010.05.040 